ARTICLE

https://doi.org/10.1038/s41467-019-13351-7

\title{
Homogeneous cobalt-catalyzed reductive amination for synthesis of functionalized primary amines
}

Kathiravan Murugesan ${ }^{1}$, Zhihong Wei ${ }^{1}$, Vishwas G. Chandrashekhar ${ }^{1}$, Helfried Neumann ${ }^{1}$ Anke Spannenberg ${ }^{1}$, Haijun Jiao ${ }^{1}$, Matthias Beller (i) ${ }^{1 \star} \&$ Rajenahally V. Jagadeesh (1) ${ }^{1 \star}$

The development of earth abundant 3d metal-based catalysts continues to be an important goal of chemical research. In particular, the design of base metal complexes for reductive amination to produce primary amines remains as challenging. Here, we report the combination of cobalt and linear-triphos (bis(2-diphenylphosphinoethyl)phenylphosphine) as the molecularly-defined non-noble metal catalyst for the synthesis of linear and branched benzylic, heterocyclic and aliphatic primary amines from carbonyl compounds, gaseous ammonia and hydrogen in good to excellent yields. Noteworthy, this cobalt catalyst exhibits high selectivity and as a result the $-\mathrm{NH}_{2}$ moiety is introduced in functionalized and structurally diverse molecules. An inner-sphere mechanism on the basis of the mono-cationic [triphos- $\mathrm{CoH}]^{+}$complex as active catalyst is proposed and supported with density functional theory computation on the doublet state potential free energy surface and $\mathrm{H}_{2}$ metathesis is found as the rate-determining step.

\footnotetext{
${ }^{1}$ Leibniz-Institut für Katalyse e.V. an der Universität Rostock, Albert-Einstein Str. 29a, Rostock D-18059, Germany. *email: matthias.beller@catalysis.de; jagadeesh.rajenahally@catalysis.de
} 
C atalysis constitutes an indispensable tool for controlling all kinds of chemical transformations ${ }^{1-11}$. Although catalysts are routinely employed in industrial production of fine and bulk chemicals as well as for exhaust gas decomposition in environmental technologies and enzymatic processes, there is a constant need for better and improved catalytic systems ${ }^{1-11}$. With respect to organometallic catalysts, their activity and selectivity are controlled to a large extent by the nature of the metal and the adjacent ligands $1,2,8-11$. In this regard, precious metals were generally believed to be crucial components ${ }^{12-23}$. Indeed, organometallic complexes based on palladium (coupling reactions) ${ }^{12-14}$, ruthenium (metathesis) $^{15,16}$, rhodium (hydrogenations and hydroformylations) ${ }^{17-19}$, platinum (hydrosilylations) ${ }^{20,21}$, and iridium (hydrogenations) $)^{22,23}$ have revolutionized organic synthesis. Key for their success is the use of a broad variety of complexes based on certain privileged ligands ${ }^{24,25}$. However, the limited availability $\left(10^{-7}-10^{-6} \%\right.$ proportion of weight in the Earth's crust) and consequently the higher price as well as the toxicity of some derivatives of these metals $^{26,27}$ have spurred interest towards the development of alternative earth abundant metal catalysts. Hence in recent years, $3 \mathrm{~d}$-metal complexes have been successfully developed for a variety of reactions including hydrogenation of carboxylic acids, esters, ketones, nitriles and olefins ${ }^{28-37}$. Nevertheless, more challenging reactions such as reductive amination with ammonia and hydrogen to access primary amines were scarcely explored ${ }^{38-44}$. In general, applying molecularly defined catalysts this transformation suffers from low selectivity to the desired product due to side reactions such as over-alkylation or reduction to the corresponding alcohols $\mathrm{s}^{38-44}$. In addition, catalyst deactivation by ammonia constitutes another problem ${ }^{45}$. Thus, to the best of our knowledge no defined homogeneous catalysts based on available 3d-metals are known for this transformation and only a few Rh-, Ir-, and Ru-complexes have been reported to catalyze amination of carbonyl compounds with ammonia and molecular hydrogen ${ }^{38-44}$. Thus, in the past reductive aminations are mainly relied on heterogeneous catalysts of precious metals $38,39,46-50$ or Raney nickel $38,39,50,51$. However, the latter material is limited in its application due to selectivity, stability and handling problems. Notably in 2017, we reported specific supported cobalt nanoparticles derived from metal organic frameworks, which proved to be general reductive amination catalysts ${ }^{52}$. In addition, very recently, Kempe ${ }^{53}$ and our group ${ }^{54}$ disclosed nickel materials. Despite these notable advancements, the development of related homogeneous non-noble metal catalysts remains interesting because of the inherent advantage regarding activity-in principle, all the individual metal centers can be active here. Furthermore, compared to homogeneous catalysts the upscaling of advanced heterogeneous materials possesses additional challenges.

Here, we report that the specific combination of cobalt and bis (diphenylphosphinoethyl)phenylphosphine (so-called linear triphos) allows the reductive amination of broad variety of aldehydes and ketones with ammonia in presence of molecular hydrogen, and this enables the synthesis of a series of functionalized and structurally diverse linear and branched benzylic, heterocyclic and aliphatic amines. The resulting primary amines serve as key precursors and central intermediates for the production of advanced chemicals, pharmaceuticals, agrochemicals, biomolecules, and materials ${ }^{55-57}$. Our present work is complementary to the known syntheses of primary benzylic and aliphatic amines by direct catalytic amination of alcohols ${ }^{58-61}$ and hydroamination using ammonia ${ }^{45,62-64}$.

\section{Results}

Catalyst and reaction design. We started our investigations to identify potentially active non-noble metal complexes based on iron, manganese and cobalt for the reaction of 4methylbenzaldehyde with ammonia and molecular hydrogen.
In general, the presence of strongly coordinating anions (e.g., halides) is inferior for hydrogen catalysis. Hence, Fe $\left(\mathrm{BF}_{4}\right)_{2} \cdot 6 \mathrm{H}_{2} \mathrm{O}$ and $\mathrm{Co}\left(\mathrm{BF}_{4}\right)_{2} \cdot 6 \mathrm{H}_{2} \mathrm{O}$ were employed as metal salts. In case of manganese, the corresponding tetrafluoroborate salt is not commercially available, therefore the inexpensive manganese(II) acetate was used. To avoid the formation of wellknown Werner-type ammonia complexes, selected privileged phosphine ligands (L1-L8) with strong coordination to the metal center were chosen (Table 1). Testing the in situ generated respective Fe-phosphorus complexes, all ligands produced inactive catalysts except for L7. This Fe-L7 system showed some activity and gave the secondary imine as the main product. However, no 4-methylbenzylamine was observed. In case of manganese, none of the ligands led to an active catalyst. Conversely, Co-complexes based on linear- and tripodaltriphos ligands (Co-L7 and Co-L8) produced the desired primary amine in 96 and 93\% yield, respectively. Next applying Co-L7, important reaction parameters such as catalyst concentration, temperature and pressure of hydrogen were tested (Supplementary Table 1, entries 2-5). Optimal results for the synthesis of 4-methylbenzylamine were achieved with a combination of $3 \mathrm{~mol} \%$ of $\mathrm{Co}\left(\mathrm{BF}_{4}\right)_{2} \cdot 6 \mathrm{H}_{2} \mathrm{O}$ and $4 \mathrm{~mol} \%$ of $\mathbf{L} 7$ at 40 bar of hydrogen, 5 bar of ammonia and $100{ }^{\circ} \mathrm{C}$. Variation of different solvents revealed the importance of alcohols, with 2,2,2-trifluoroethanol (TFE) as the best one (Supplementary Table 2). Notably, this 3d-metal catalyst system allows performing reductive aminations with ammonia under milder reaction conditions compared to all previously reported precious metal complexes ${ }^{40-44}$.

To know the structure of the in situ-formed cobalt-triphos complex (C-L7) and to understand its mode of reactivity, the molecularly defined Co-L7 complex A was prepared (Methods). Surprisingly, the single crystal analysis of complex A revealed the coordination of two phosphine ligands (1:2 ratio of Co:L7) to the Co center, in which one ligand coordinates via three phosphorus atoms and the second ligand via two phosphorus atoms (Supplementary methods, complex A). Performing the crystallization attempts without vigorous exclusion of air gave the partially oxidized phosphine ligand, which forms cobalt complex B. Both complexes $\mathbf{A}$ and $\mathbf{B}$ were observed as cobalt (II) species consisting of a complex dication and two tetrafluoroborates. Comparing these two defined complexes in the benchmark reaction, complex $\mathbf{A}$ exhibited similar activity and selectivity to that of the in situ generated Co-triphos system, while $\mathbf{B}$ is much less active and produced only $70 \%$ of the corresponding secondary imine 4 as the sole product (Supplementary Table 1, entries 8-9). This indicates a major deactivation of the catalyst by oxidation of phosphine to phosphine oxide. poisoning experiments were performed. As expected, adding $\mathrm{Hg}$ or $50 \mathrm{~mol} \% \mathrm{PPh}_{3}$ to the reaction under standard conditions did not affect the activity or selectivity of complex A (Supplementary Table 4).

Synthesis of linear primary amines from aldehydes. After having identified the active homogeneous cobalt catalyst system $[\mathrm{L} 7 \mathrm{CoH}]^{+}$, we explored its general applicability for the preparation of primary amines.

As shown in Fig. 1, substituted, functionalized and structurally diverse aldehydes underwent amination to produce linear primary amines in good to excellent yields at $100-120^{\circ}$ C. Substrates containing either electron-donating or electronwithdrawing groups were successfully reacted and gave the desired products. The tested halogenated aldehydes were well tolerated and produced corresponding amines without significant dehalogenations $(<5 \%)$ (Fig. 1, products $\mathbf{1 2 - 1 5}$ and 
Table 1 Reductive amination of 4-methylbenzaldehyde with in situ generated complexes.

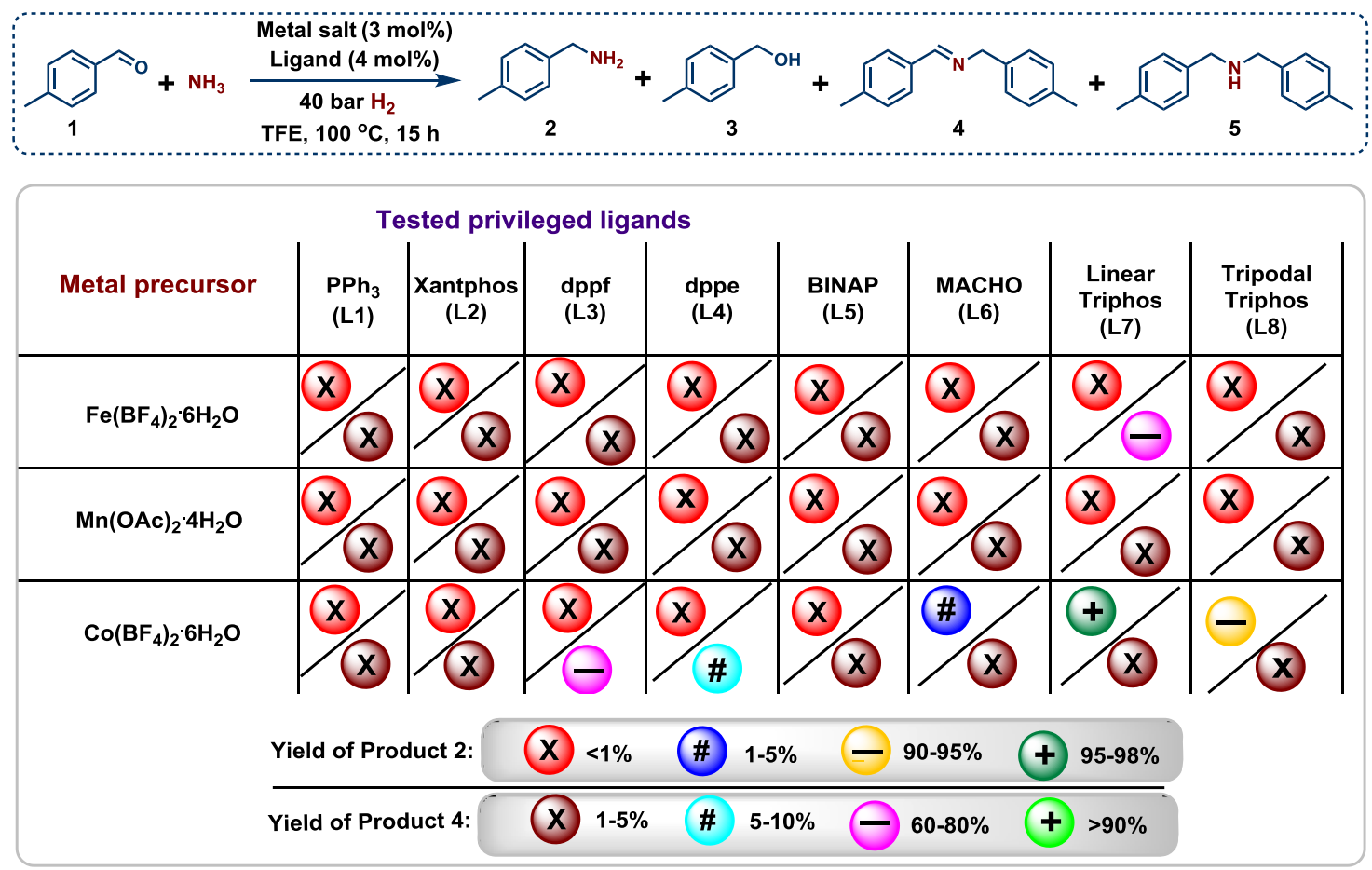<smiles>c1ccc(P(c2ccccc2)c2ccccc2)cc1</smiles>

L1

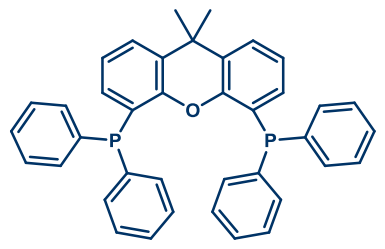

L2<smiles>c1ccc(P(c2ccccc2)c2cccc(P(c3ccccc3)c3ccccc3)c2)cc1</smiles>

L3<smiles>c1ccc(P(CCP(c2ccccc2)c2ccccc2)c2ccccc2)cc1</smiles>

L4<smiles>c1ccc(P(c2ccccc2)c2ccc3ccccc3c2-c2cccc3ccccc23)cc1</smiles>

L5<smiles>c1ccc(P(CCNCCP(c2ccccc2)c2ccccc2)c2ccccc2)cc1</smiles>

L6<smiles>c1ccc(P(CCP(c2ccccc2)c2ccccc2)c2ccccc2)cc1</smiles>

L7<smiles>CC(CP(c1ccccc1)c1ccccc1)(CP(c1ccccc1)c1ccccc1)CP(c1ccccc1)c1ccccc1</smiles>

L8

Reaction conditions: a $0.5 \mathrm{mmol} 4$-methylbenzaldehyde, 3 mol\% metal salt, 4 mol\% ligand, 5 bar $\mathrm{NH}_{3}, 40$ bar $\mathrm{H}_{2}, 2 \mathrm{~mL}$ TFE, $100^{\circ} \mathrm{C}, 15 \mathrm{~h}, \mathrm{GC}$ yields using $\mathrm{n}$-hexadecane as standard.

21). For any catalyst applicable in organic synthesis as well as drug discovery, achieving a high degree of chemoselectivity is important, yet challenging. To showcase this aspect, reductive aminations of various functionalized aldehyde were performed. Reducible groups such as $\mathrm{C}-\mathrm{C}$ double bonds and esters remained untouched. In addition, thioethers and boronic ester groups are well tolerated (Fig. 1; products 22-25). Primary amines of 3,4-methylenedioxy and benzo-1,4-dioxane, which represent versatile motifs in many drugs and natural products, were prepared in up to $96 \%$ yield (products 26-28). Finally, also aliphatic aldehydes produced the corresponding amines (Fig. 1, products 28-30).
Synthesis of branched primary amines from ketones. Compared to aldehydes, amination of ketones is more challenging, because the hydrogenation of the sterically hindered imine is more difficult. Nevertheless, this Co-triphos catalyst system is active and selective for the reductive amination of ketones, too (Figs. 2, 3). As a result, 30 ketones were efficiently aminated to produce branched primary amines in high yields. Substrates bearing easily coordinating groups to the metal such as $-\mathrm{NH}_{2},-\mathrm{OH}$ and phenolic groups as well as pyridines gave $90-95 \%$ yield of corresponding amines (Fig. 2; products $35-36$ and 40-43). Further aliphatic ketones smoothly gave the branched amines in up to $93 \%$ yield (Fig. 2; products 48-52). 


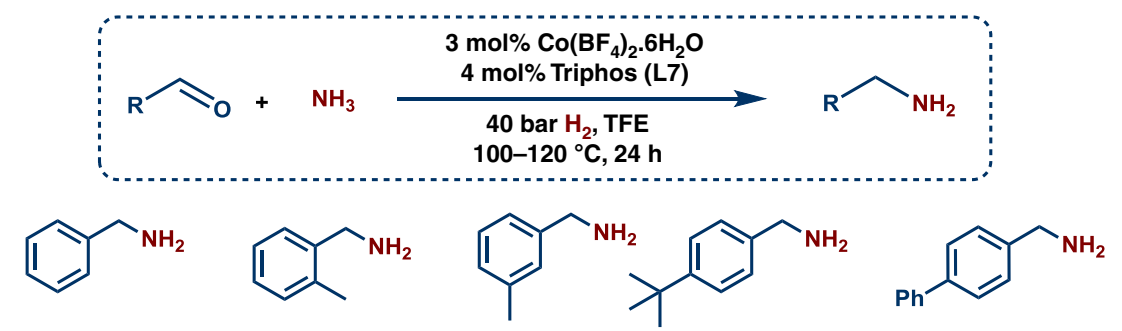<smiles>NCc1ccc(Cl)cc1</smiles>

$11: 92 \%^{c} \quad 12: 93 \% \quad 13: 91 \%$<smiles>NCc1ccc(OC(F)(F)F)cc1</smiles><smiles>COc1ccc(CN)cc1</smiles><smiles>NCc1ccc(OCc2ccccc2)cc1</smiles>

16: $95 \%$

$17: 93 \%^{c}$<smiles>COc1ccc(CN)cc1OC</smiles>

18: $84 \%^{b, c}$
15: $90 \%{ }^{c}$<smiles>COc1cc(CN)cc(OC)c1OC</smiles>

19: $92 \%^{c}$<smiles>COc1ccc(CN)cc1O</smiles>

20: $95 \%^{c}$<smiles>COC(=O)c1ccc(CN)cc1</smiles>

24: $94 \%^{\text {b }}$<smiles>COc1cc(CN)ccc1OCc1c(F)cccc1Cl</smiles>

21: $87 \%^{c}$<smiles>CC(C)(C)C(=O)OB1OC(C)(C)C(C)(C)O1</smiles>

25: $91 \%$<smiles>CSc1ccc(CN)cc1</smiles>

22: $95 \%^{\mathrm{c}}$<smiles>NCc1ccc2c(c1)OCO2</smiles>

26: $96 \%$<smiles>NCc1ccc(/C=C/c2ccccc2)cc1</smiles>

23: $87 \%$<smiles>CC(CN)Cc1ccc2c(c1)OCO2</smiles>

28: $92 \%$<smiles>CC(CN)Cc1ccc(C(C)(C)C)cc1</smiles><smiles>CC(CCN)c1ccccc1</smiles>

30: $85 \%^{c}$<smiles>NCc1ccc2c(c1)OCCO2</smiles>

27: $94 \%$

Fig. 1 Cobalt-triphos catalyzed synthesis of primary amines from aldehydes. Reaction conditions: a $0.5 \mathrm{mmol}$ aldehyde, $3 \mathrm{~mol} \% \mathrm{Co}\left(\mathrm{BF}_{4}\right)_{2} \cdot 6 \mathrm{H}_{2} \mathrm{O}, 4 \mathrm{~mol} \%$ triphos (L7), 5-7 bar $\mathrm{NH}_{3}, 40$ bar $\mathrm{H}_{2}, 2 \mathrm{~mL}$ degassed TFE, $100^{\circ} \mathrm{C}, 24 \mathrm{~h}$. ' $\mathrm{GC}$ yields using $\mathrm{n}$-hexadecane as standard. 'Same as 'a' at $120^{\circ} \mathrm{C}$. Isolated as free amines and converted to hydrochloride salts. Corresponding hydrochloride salts were subjected to NMR analysis.

Amination of life science molecules and steroid-derivatives. For any potential catalyst, its utility for the refinement of complex molecules is of central importance. In order to prove the general applicability of our catalytic system, we performed the amination of structurally complex ketones, including existing drug and steroid-based molecules (Fig. 3). Gratifyingly, cobalt-triphos is highly efficient and selective for the amination of drugs such as Nabumetone, Pentoxifylline, and Azaperone as well as Estrone and Stanolone-based steroid derivatives (Fig. 3). This methodology offers many opportunities for late stage functionalization of life science and bioactive molecules.

\section{Discussion}

Since $\mathrm{Co}^{\mathrm{II}}\left(\mathrm{BF}_{4}\right)_{2} \cdot 6 \mathrm{H}_{2} \mathrm{O}$ is the most active cobalt salt for the reductive amination of 4-methylbenzaldehyde (Supplementary Table 3), the mono-cationic hydride $[\mathrm{L7CoH}]^{+}(\mathrm{I})$ complex is proposed as the active catalyst along the catalytic cycle (Fig. 4) on the basis of our results as well as those of the previously reported cobalt/phosphine-catalyzed hydrogenation reactions $31,65-68$, Starting from the cationic complex $\mathbf{A}\left[(\mathrm{L} 7)_{2} \mathrm{Co}^{\mathrm{II}}\right]^{2+}$, the first step is the dissociation of one L7 ligand and the formation of the active cobalt hydride catalyst $[\mathrm{L} 7 \mathrm{CoH}]^{+}(\mathrm{I})$ in the presence of ammonia and $\mathrm{H}_{2}$. Without ammonia present, no hydrogenation of 4-methylbenzaldehyde to the corresponding alcohol occurred (Supplementary Table 1, entries 6-7).Next, the primary imine formed from 1 and ammonia generates complex II. In agreement with previous work using ruthenium complexes and based on our DFT calculations, we propose first substrate coordination and then beta hydride addition. Finally, coordination of $\mathrm{H}_{2}$ followed by hydrogenolysis releases the primary amine and regenerates catalytically active species I.

To understand the detailed mechanism, we carried out B3PW91 density functional theory computations for the hydrogenation of phenylmethanimine $(\mathrm{Ph}-\mathrm{CH}=\mathrm{NH})$ generated from benzaldehyde and $\mathrm{NH}_{3}$. In our calculations we used the real-size complexes and substrate and calculated the catalytic cycle in the gas phase as well as in a solution of 2,2,2-trifluoroethanol (dielectric constant $=26.69$ ) without and with van de Waals dispersion correction. All these data are listed in Supplementary Information. The potential energy surfaces show the same trend and shape but differ quantitatively. In the gas phase and in a solution, the apparent barriers are close (96 vs. $108 \mathrm{~kJ} / \mathrm{mol}$ ), while that in a solution with dispersion correction is highly 


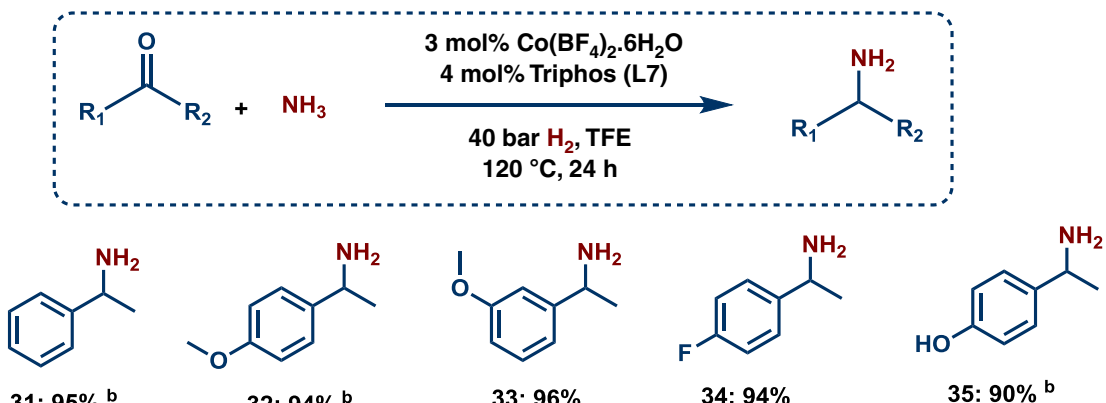

$31: 95 \% b$

$32: 94 \%^{b}$<smiles>CC(N)c1cccnc1</smiles>

36: $95 \%$ b<smiles>CSc1ccc(C(C)N)cc1</smiles>

37: $94 \%$

38: $86 \%$ c<smiles>CC(N)c1ccc(S(C)(=O)=O)cc1</smiles><smiles>CC(N)CCc1ccc(O)cc1</smiles><smiles>COc1cc(CCC(C)N)ccc1O</smiles>

41: $94 \%$<smiles>Cc1ccc(CC(N)c2ccccc2)cc1</smiles>

45: $89 \%$<smiles>CC1=C(CCC(C)N)C(C)(C)CCC1</smiles>

49: $77 \%$ c<smiles>COc1cc(CC(C)N)ccc1O</smiles>

42: $93 \%$<smiles>CC(N)c1cc(Cl)c(N)c(Cl)c1</smiles>

43: $88 \%{ }^{\circ}$<smiles>CC1(C(N)c2ccccc2)CCCCC1</smiles>

47: $92 \%$<smiles>CCCCC(N)c1ccccc1</smiles>

44: $87 \%$<smiles>NC(Cc1ccccc1)Cc1ccccc1</smiles>

46: $91 \%$<smiles>NC1C2C=CC1CC2</smiles>

50: $96 \%$ b<smiles>CCCCC(N)CCCC</smiles>

51: $90 \%$<smiles>CC(C)(C)C1CCC(N)CC1</smiles>

48: $93 \%(70: 30)^{d}$

Fig. 2 Synthesis of primary amines from ketones using cobalt-triphos catalyst. Reaction conditions: ${ }^{\mathrm{a}} 0.5 \mathrm{mmol}$ ketone, $3 \mathrm{~mol} \% \mathrm{Co}\left(\mathrm{BF}_{4}\right)_{2} \cdot 6 \mathrm{H}_{2} \mathrm{O}, 4 \mathrm{~mol} \%$ triphos (L7), 5-7 bar $\mathrm{NH}_{3}, 40$ bar $\mathrm{H}_{2}, 2 \mathrm{~mL}$ degassed TFE, $120^{\circ} \mathrm{C}, 24 \mathrm{~h}$. bGC yields using $\mathrm{n}$-hexadecane as standard. 'Same as 'a' with 50 bar $\mathrm{H}_{2}$.

dDiastereomeric ratio. Isolated as free amines and converted to hydrochloride salts. Corresponding hydrochloride salts were subjected to NMR analysis.<smiles>CC(N)CCc1c[nH]c2ccccc12</smiles>

53: $88 \%$<smiles>COc1ccc2cc(CCC(C)N)ccc2c1</smiles>

54: $92 \%$ (Nabumetone- $\mathrm{NH}_{2}$ )<smiles>CC(N)CCCCn1c(=O)c2c(ncn2C)n(C)c1=O</smiles><smiles>NC(CCCN1CCN(c2ccccn2)CC1)c1ccc(F)cc1</smiles>

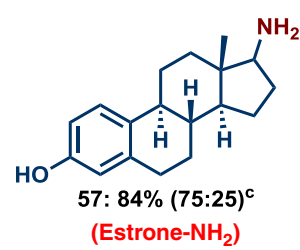<smiles>CC(C)=CCCC(C)N</smiles>

52: $88 \%$

(Estrone- $\mathrm{NH}_{2}$ )

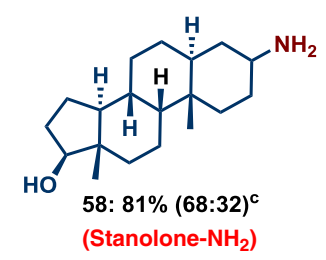

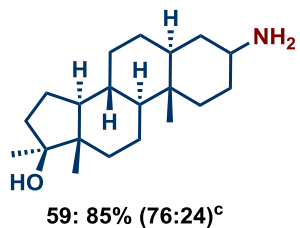

(17 $\alpha$-Methylandrostanolone- $\mathrm{NH}_{2}$ )

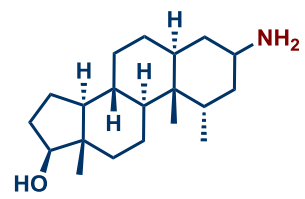

60: $78 \%(65: 35)^{c}$

( $1 \alpha$-Methylandrostanolone- $\mathrm{NH}_{2}$ )

Fig. 3 Co-catalyzed amination of bioactive compounds. Reaction conditions: a 0.5 mmol substrate, 3 mol\% $\mathrm{Co}\left(\mathrm{BF}_{4}\right)_{2} \cdot 6 \mathrm{H}_{2} \mathrm{O}, 4 \mathrm{~mol} \%$ triphos $(\mathbf{L 7})$, $5-7$ bar $\mathrm{NH}_{3}, 40$ bar $\mathrm{H}_{2}, 2 \mathrm{~mL}$ degassed TFE, $120^{\circ} \mathrm{C}, 24 \mathrm{~h}$. bSame as 'a' with 50 bar $\mathrm{H}_{2}$. 'Diastereomeric ratio. Isolated as free amines and converted to hydrochloride salts. Corresponding hydrochloride salts were subjected to NMR analysis. 


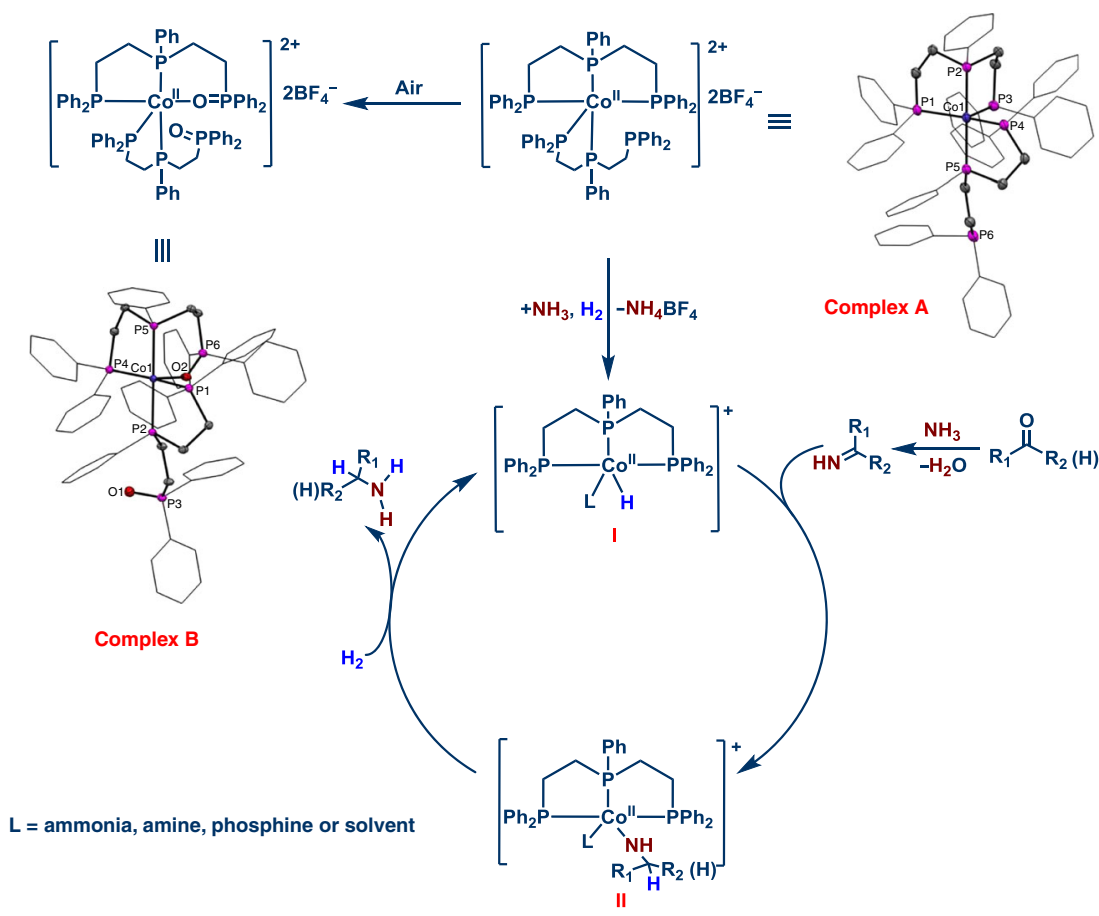

Fig. 4 Proposed reaction mechanism for the Co-triphos catalysed reductive amination. Molecular structure of the cation of complexes $\mathrm{A}$ and $\mathrm{B}$. Displacement ellipsoids are drawn at the $30 \%$ probability level; phenyl rings are shown as wireframe; hydrogen atoms are omitted for clarity.

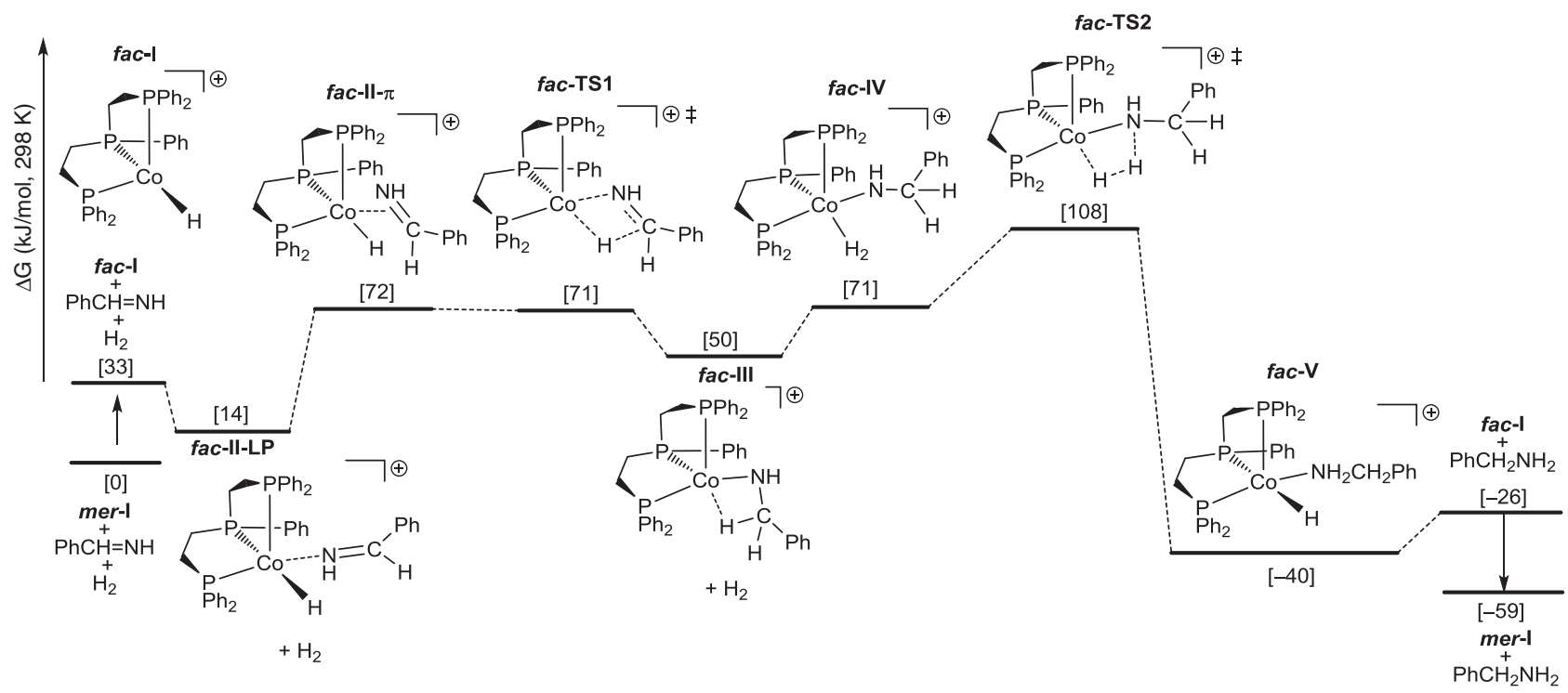

Fig. 5 Gibbs free energy surface for $\mathrm{Ph}-\mathrm{CH}=\mathrm{NH}$ hydrogenation in TFE solvation. $\mathrm{Ph}-\mathrm{CH}=\mathrm{NH}$ hydrogenation by using mono-cationic [triphos- $\mathrm{CoH}]^{+}$as active catalyst.

underestimated $(29 \mathrm{~kJ} / \mathrm{mol})$. In addition to the mono-cationic catalyst $[\mathrm{L} 7 \mathrm{CoH}]^{+}$, we included the di-cationic catalyst $[\mathrm{L} 7 \mathrm{Co}]^{2+}$, and the apparent barriers are much too high $(128 \mathrm{~kJ} / \mathrm{mol}$ in the gas phase and $212 \mathrm{~kJ} / \mathrm{mol}$ in a solution, $122 \mathrm{~kJ} / \mathrm{mol}$ in a solution with dispersion correction, Supplementary Figs. 8-10) and this catalytic cycle can be discarded. We therefore discussed our results of the mono-cationic complex $[\mathrm{L} 7 \mathrm{CoH}]^{+}(\mathbf{I})$ in solvation. Since complex I has $f a c$ and mer conformations under equilibrium, we computed both catalytic cycles and found that mer-I is more stable than $\boldsymbol{f a c}$-I by $33 \mathrm{~kJ} / \mathrm{mol}$, while $\boldsymbol{f a c}$-I based catalytic cycle has lower apparent barrier than that of mer-I (108 vs. 140 $\mathrm{kJ} / \mathrm{mol}$, Supplementary Fig. 6). On the basis of Curtin-Hammett principle, the fac-I based catalytic cycle is more preferred kinetically (Fig. 5). Starting from the mer-I, the coordination of $\mathrm{Ph}$ $-\mathrm{CH}=\mathrm{NH}$ to form fac-II-LP is endergonic by $14 \mathrm{~kJ} / \mathrm{mol}$, and the formation of $\pi$-coordinated fac-II- $\pi$ is endergonic by $72 \mathrm{~kJ} /$ mol. The Gibbs free energy barrier of $\mathrm{Ph}-\mathrm{CH}=\mathrm{NH}$ insertion into fac-I is $71 \mathrm{~kJ} / \mathrm{mol}$. The formation of intermediate fac-III with agostic interaction is endergonic by $50 \mathrm{~kJ} / \mathrm{mol}$. In the second step, $\mathrm{H}_{2}$ coordination to form fac-IV is endergonic by $71 \mathrm{~kJ} / \mathrm{mol}$. The metathesis step has Gibbs free energy barrier of $108 \mathrm{~kJ} / \mathrm{mol}$ for fac-IV. The formation of fac-V is exergonic by $40 \mathrm{~kJ} / \mathrm{mol}$. The release of amine from complex fac-V with the regeneration of mer-I is exergonic $59 \mathrm{~kJ} / \mathrm{mol}$. The transition state of $\mathrm{H}_{2}$ 
metathesis represents the highest point on the Gibbs free energy surface and is the rate-determining transition state; and the apparent Gibbs free energy barrier is $108 \mathrm{~kJ} / \mathrm{mol}$ from mer-I. On the basis of our reaction conditions $\left(100-120^{\circ} \mathrm{C}, 40\right.$ bar $\mathrm{H}_{2}$ and $15-24 \mathrm{~h}$ reaction time), the barrier is reasonable. This catalytic cycle is similar with that proposed by Hanson and Jones. It is noted that the result with GD3BJ correction (Supplementary Figs. 9 and 12) has extremely low apparent barrier $(29 \mathrm{~kJ} / \mathrm{mol})$.

In conclusion, we demonstrate that reductive aminations for the preparation of primary amines can be easily performed using non-noble metal-based homogeneous catalysts. Key to success for this achievement is the use of a specific metal ligand system (cobalt-triphos), which enables the synthesis of a broad variety of linear and branched benzylic, heterocyclic, and aliphatic amines starting from inexpensive and easily accessible carbonyl compounds, gaseous ammonia and hydrogen. Remarkably, this cobalt-triphos system works under milder reaction conditions compared to the previously reported precious homogeneous catalysts for reductive amination with ammonia. Isolation of an active pre-catalyst revealed the fast oxidation of phosphine moiety as a potential deactivation pathway of the catalyst. Density functional theory computations verified the proposed innersphere mechanism with the $\mathrm{H}_{2}$ metathesis step as the ratedetermining step.

\section{Methods}

General considerations. Unless specified, all substrates were obtained commercially from various chemical companies and their purity has been checked before use. Unless otherwise stated, all commercial reagents were used as received without purification. All catalytic reactions were carried out in $300 \mathrm{~mL}$ and $100 \mathrm{~mL}$ autoclaves (PARR Instrument Company). In order to avoid unspecific reactions, catalytic reactions were carried out either in glass vials, which were placed inside the autoclave, or glass/Teflon vessel fitted autoclaves. GC conversion and yields were determined by GC-FID, HP6890 with FID detector, column HP530 m × $250 \mathrm{~mm} \times$ $0.25 \mu \mathrm{m} .{ }^{1} \mathrm{H},{ }^{13} \mathrm{C},{ }^{19} \mathrm{~F}$ NMR data were recorded on a Bruker ARX 300 and Bruker ARX 400 spectrometers using DMSO- $\mathrm{d}_{6}, \mathrm{CD}_{3} \mathrm{OD}$ and $\mathrm{CDCl}_{3}$ solvents. HRMS data were recorded on (1) ESI-HRMS: HPLC System 1200 /ESI-TOF-MS 6210 (Agilent).

X-ray crystal structure analysis of Complex A and Complex B: Data were collected on a Bruker Kappa APEX II Duo diffractometer. The structures were solved by direct methods (SHELXS-97: Sheldrick, G. M. Acta Cryst. 2008, A64, 112.) and refined by full-matrix least-squares procedures on $F^{2}$ (SHELXL-2014: Sheldrick, G. M. Acta Cryst. 2015, C71, 3.). XP (Bruker AXS) and Mercury (Macrae, C. F., Edgington, P. R., McCabe, P., Pidcock, E., Shields, G. P., Taylor, R., Towler, M., van de Streek, J. J. Appl. Cryst. 2006, 39, 453.) were used for graphical representations.

Synthesis of cobalt (II) complexes A and B. In $100 \mathrm{~mL}$ dried schlenk tube, $340.63 \mathrm{mg}$ of $\mathrm{Co}\left(\mathrm{BF}_{4}\right)_{2} \cdot 6 \mathrm{H}_{2} \mathrm{O}(1.0 \mathrm{mmol})$ was stirred in $40 \mathrm{~mL}$ of THF (dry and degassed) for $5 \mathrm{~min}$ under argon to dissolve metal salt completely to give pink colored solution. Then, $535.55 \mathrm{mg}$ of triphos ((phenylphosphanediyl) bis(ethane2,1-diyl)) bis (diphenylphosphane) $(1.0 \mathrm{mmol})$ was added to the solution of metal precursor. Upon adding the ligand, the pink colored catalyst precursor solution was turned to brown colored solution. To this, another $20 \mathrm{~mL}$ of THF (dry and degassed) was added and stirring was continued for $2 \mathrm{~h}$ at RT. In $10 \mathrm{~min}$ of stirring time, the ligand was completely dissolved. After $1 \mathrm{~h}$ of stirring, the brown color solid was started to form along with some brown color crystal type material. After the completion of the reaction, the reaction mixture was stored at $-30{ }^{\circ} \mathrm{C}$ for overnight. The THF solution was removed by using syringe and the complex formed was washed with $10 \mathrm{~mL}$ of THF (dry and degassed). Further, it was washed with dry and degassed hexane $(2 \times 10 \mathrm{~mL})$ and then dried under high vacuum for 6 $\mathrm{h}$, to get a brown color solid in $48-50 \%$ yield. The dark brown crystals were observed along with brown solid. These crystals were separated carefully and recrystallized with dry and degassed ethanol under argon. The crystals obtained were suitable for X-ray analysis. The oxide species of complex B (yellow crystals) were formed during the crystallization, when we carried out in normal solvent without dry and degas.

General procedure for synthesis of primary amines. The magnetic stirring bar and $\mathrm{Co}\left(\mathrm{BF}_{4}\right)_{2} \cdot 6 \mathrm{H}_{2} \mathrm{O}(3 \mathrm{~mol} \%)$ and linear triphos ((phenylphosphanediyl)bis (ethane-2,1-diyl))bis(diphenylphosphane) $(4 \mathrm{~mol} \%)$ were transferred to $8 \mathrm{~mL}$ glass vial and then $2 \mathrm{~mL}$ degassed (degassed under argon for 15 minutes before adding) trifluoroethanol (TFE) solvent was added. The colorless solution turned in to pale yellow first and then finally to brown color by stirring under argon for $15 \mathrm{~min}$.
Then, $0.5 \mathrm{mmol}$ corresponding carbonyl compound was added to the reaction vial. The vial was fitted with septum, cap, and needle. The reaction vials ( 8 vials with different substrates at a time) were placed into a $300 \mathrm{~mL}$ autoclave. The autoclave was flushed with hydrogen twice at 30 bar pressure and then it was pressurized with 5-7 bar ammonia gas and 40 bar hydrogen. The autoclave was placed into an aluminum block preheated at $130^{\circ} \mathrm{C}$ (placed 30 minutes before counting the reaction time in ordered to attain reaction temperature) and the reactions were stirred for a required time. During the reaction, the inside temperature of the autoclave was measured to be $120^{\circ} \mathrm{C}$ and this temperature was used as the reaction temperature. After the completion of the reactions, the autoclave was cooled to room temperature. The remaining ammonia and hydrogen were discharged and the vials containing reaction products were removed from the autoclave. The reaction mixture was filtered off and washed thoroughly with ethyl acetate. The reaction products were analyzed by GC-MS. The crude product was purified by flash column chromatography. The corresponding primary amines were converted to their respective hydrochloride salt and characterized by NMR and GC-MS analysis. For converting into hydrochloride salt of amine, 1-2 mL methanolic $\mathrm{HCl}$ $(0.5 \mathrm{M} \mathrm{HCl}$ in methanol) was added to the ether solution of respective amine and stirred at room temperature for $4-5 \mathrm{~h}$. Then, the solvent was removed and the resulted hydrochloride salt of amine is dried under high vacuum. The yields were determined by GC for the selected amines: After completion of the reaction, nhexadecane $(100 \mu \mathrm{L})$ as standard was added to the reaction vials and the reaction products were diluted with ethyl acetate followed by filtration using a plug of silica and then analyzed by GC.

Note: Dry and degassed solvent should necessary for this transformation to achieve high yield and reactivity. Similarly, dry ligand and metal salts have been employed. And also well-defined complex-A is more active than in situ prepared system and Complex-A should be stored at $-30^{\circ} \mathrm{C}$ for maintaining its stability for a longer time.

Computational methods and models. All calculations were carried out with Gaussian 09 program $^{69}$. Geometry optimization was carried out in gas phase at the B3PW91 ${ }^{70}$ level with the TZVP 71 basis set. All optimized structures were further characterized either as energy minimums without imaginary frequencies or transition states with only one imaginary frequency by frequency calculations, which provided zero-point vibrational energies and thermodynamic corrections to enthalpy and Gibbs free energy at $298.15 \mathrm{~K}$ under 1 atmosphere. On the basis of B3PW91/TZVP geometries in gas phase, two types single-point energies were calculated, one including solvation effect of 2,2,2trifluoroethanol (TFE) as solvent (dielectric constant $\varepsilon=26.69^{72}$ ) based on solute electron density (SMD) at the B3PW91/Def2-TZVP ${ }^{73}$ level (B3PW91SMD) and one including solvation ${ }^{73}$ and van der Waals dispersion ${ }^{74}$ correction for the effect of phenyl substitution (B3PW91-SMD-D3). The Gibbs free energies were further corrected to standard state in solution with a standard concentration of $1 \mathrm{~mol} / \mathrm{L}(p=24.5 \mathrm{~atm})$ from standard state in gas phase $(p=1 \mathrm{~atm})$. Both mono-cationic hydride $[\mathrm{L} 7 \mathrm{CoH}]^{+}(\mathrm{L} 7=$ triphos $)$ and di-cationic $\left[\mathrm{L} 7 \mathrm{Co}(\mathrm{H})_{2}\right]^{2+}$ complexes are proposed as potential active catalysts (Table 1).

\section{Data availability}

The data that support the findings of this study are available from the corresponding authors (M.B. and R.V.J.) upon reasonable request. The X-ray crystallographic coordinates for structures reported in this study have been deposited at the Cambridge Crystallographic Data Centre (CCDC), under deposition numbers CCDC 18974921897493. These data can be obtained free of charge from The Cambridge Crystallographic Data Centre via www.ccdc.cam.ac.uk/data_request/cif.

Received: 30 April 2019; Accepted: 4 November 2019; Published online: 29 November 2019

\section{References}

1. Beller, M. \& Bolm, C. Transition Metals for Organic Synthesis (Wiley-VCH, NewYork, 2008)

2. Negishi, E.-i Magical power of transition metals: past, present, and future (Nobel lecture). Angew. Chem. Int. Ed. 50, 6738-6764 (2011).

3. Smith, G. V., Notheisz, F. Heterogeneous Catalysis in Organic Chemistry (Academic Press, San Diego, 1999).

4. Ertl, G., Knözinger, H., Weitkamp, J. Environmental Catalysis (WILEY-VCH, 2008).

5. Drauz, K., Gröger, H., May, O. Enzyme Catalysis in Organic Synthesis (Wiley$\mathrm{VCH}, 2012$ )

6. Boersma, A. J., Megens, R. P., Feringa, B. L. \& Roelfes, G. DNA-based asymmetric catalysis. Chem. Soc. Rev. 39, 2083-2092 (2010).

7. James, T., van Gemmeren, M. \& List, B. Development and applications of disulfonimides in enantioselective organocatalysis. Chem. Rev. 115, 9388-9409 (2015). 
8. Leeuwen, P. W. N. M. V. Homogeneous Catalysis: Understanding the Art (Kluwer Academic Publishers, Boston, 2004).

9. Cornils, B. \& Herrmann, W. A. Applied homogeneous Catalysis with Organometallic Compounds (Wiley-VCH, Weinheim, 1996).

10. Alig, L., Fritz, M. \& Schneider, S. First-row transition metal (de)hydrogenation catalysis based on functional pincer ligands. Chem. Rev. 119, 2681-2751 (2019).

11. O'Reilly, M. E. \& Veige, A. S. Trianionic pincer and pincer-type metal complexes and catalysts. Chem. Soc. Rev. 43, 6325-6369 (2014).

12. de Meijere, A. \& Diederich, F. Metal-Catalyzed Cross-Coupling Reactions (Wiley-VCH, ed. 2, Weinheim, 2004).

13. Ruiz-Castillo, P. \& Buchwald, S. L. Applications of palladium-catalyzed C-N cross-coupling reactions. Chem. Rev. 116, 12564-12649 (2016).

14. Hartwig, J. F. Evolution of a fourth generation catalyst for the amination and thioetherification of aryl halides. Acc. Chem. Res. 41, 1534-1544 (2008).

15. Alcaide, B., Almendros, P. \& Luna, A. Grubbs' ruthenium-carbenes beyond the metathesis reaction: less conventional non-metathetic utility. Chem. Rev. 109, 3817-3858 (2009)

16. Ogba, O. M., Warner, N. C., O'Leary, D. J. \& Grubbs, R. H. Recent advances in ruthenium-based olefin metathesis. Chem. Soc. Rev. 47, 4510-4544 (2018).

17. Franke, R., Selent, D. \& Börner, A. Applied hydroformylation. Chem. Rev. 112, 5675-5732 (2012).

18. Leeuwen, P. W. N. M. V. \& Claver, C. Rhodium Catalyzed Hydroformylation (Springer Netherlands, 2002).

19. Etayo, P. \& Vidal-Ferran, A. Rhodium-catalysed asymmetric hydrogenation as a valuable synthetic tool for the preparation of chiral drugs. Chem. Soc. Rev. 42, 728-754 (2013).

20. Troegel, D. \& Stohrer, J. Recent advances and actual challenges in late transition metal catalyzed hydrosilylation of olefins from an industrial point of view. Coord. Chem. Rev. 255, 1440-1459 (2011).

21. Marciniec, B., Maciejewski, H., Pietraszuk, C., Pawluc, P. Hydrosilylation: A Comprehensive Review on Recent Advances (Springer: London, 2009).

22. Roseblade, S. J. \& Pfaltz, A. Iridium-catalyzed asymmetric hydrogenation of olefins. Acc. Chem. Res. 40, 1402-1411 (2007).

23. Hopmann, K. H. \& Bayer, A. Enantioselective imine hydrogenation with iridium-catalysts: reactions, mechanisms and stereocontrol. Coord. Chem. Rev. 268, 59-82 (2014).

24. Zhou, Q.-L. Privileged Chiral Ligands and Catalysts (Wiley-VCH, Weinheim, 2011).

25. Privileged ligands. https://www.sigmaaldrich.com/content/dam/sigmaaldrich/ docs/Aldrich/Brochure/al_chemfile_v6_n8.pdf (2006).

26. Precious metals management (pmm). www.platinum.matthey.com. (2019).

27. Metals market prices, forecasts \& analysis. www.metalprices.com. (2019).

28. Gebbink, R. J. M. K. \& Moret, M.-E. Non-Noble Metal Catalysis Molecular Approaches and Reactions (Wiley-VCH, 2019).

29. Beller, M. Introduction: first row metals and catalysis. Chem. Rev. 119, 2089-2089 (2019).

30. Irrgang, T. \& Kempe, R. 3d-Metal catalyzed N- and C-alkylation reactions via borrowing hydrogen or hydrogen autotransfer. Chem. Rev. 119, 2524-2549 (2019).

31. Korstanje, T. J., van der Vlugt, Ivar, Elsevier, J. \& de Bruin, C. J. B. Hydrogenation of carboxylic acids with a homogeneous cobalt catalyst. Science 350, 298-302 (2015).

32. Ai, W., Zhong, R., Liu, X. \& Liu, Q. Hydride transfer reactions catalyzed by cobalt complexes. Chem. Rev. 119, 2876-2953 (2019).

33. Jerphagnon, T., Pizzuti, M. G., Minnaard, A. J. \& Feringa, B. L. Recent advances in enantioselective copper-catalyzed 1,4-addition. Chem. Soc. Rev. 38, 1039-1075 (2009).

34. Wei, D. \& Darcel, C. Iron catalysis in reduction and hydrometalation reactions. Chem. Rev. 119, 2550-2610 (2019).

35. Liu, W., Sahoo, B., Junge, K. \& Beller, M. Cobalt complexes as an emerging class of catalysts for homogeneous hydrogenations. Acc. Chem. Res. 51, 1858-1869 (2018).

36. Cahiez, G. \& Moyeux, A. Cobalt-catalyzed cross-coupling reactions. Chem. Rev. 110, 1435-1462 (2010). 51.

37. Chirik, P. \& Morris, R. Getting down to earth: the renaissance of catalysis with abundant metals. Acc. Chem. Res. 48, 2495-2495 (2015).

38. Gomez, S., Peters, J. A. \& Maschmeyer, T. The reductive amination of aldehydes and ketones and the hydrogenation of nitriles: mechanistic aspects and selectivity control. Adv. Synth. Catal. 344, 1037-1057 (2002).

39. Alinezhad, H., Yavari, H. \& Salehian, F. Recent advances in reductive amination catalysis and its applications. Curr. Org. Chem. 19, 1021-1049 (2015).

40. Gross, T., Seayad, A. M., Ahmad, M. \& Beller, M. Synthesis of primary amines: first homogeneously catalyzed reductive amination with ammonia. Org. Lett. 4, 2055-2058 (2002).
41. Gallardo-Donaire, J., Ernst, M., Trapp, O. \& Schaub, T. Direct synthesis of primary amines via ruthenium-catalysed amination of ketones with ammonia and hydrogen. Adv. Synth. Catal. 358, 358-363 (2016).

42. Gallardo-Donaire, J. et al. Direct asymmetric ruthenium-catalyzed reductive amination of alkyl-aryl ketones with ammonia and hydrogen. J. Am. Chm. Soc. 140, 355-361 (2018).

43. Senthamarai, T. et al. Simple ruthenium-catalyzed reductive amination enables the synthesis of a broad range of primary amines. Nat. Commun. $\mathbf{9}$ 4123 (2018)

44. Tan, X. et al. Asymmetric synthesis of chiral primary amines by rutheniumcatalyzed direct reductive amination of alkyl aryl ketones with ammonium salts and molecular H2. J. Am. Chm. Soc. 140, 2024-2027 (2018).

45. Klinkenberg, J. L. \& Hartwig, J. F. Catalytic organometallic reactions of ammonia. Angew. Chem., Int. Ed. 50, 86-95 (2011)

46. Nakamura, Y., Kon, K., Touchy, A. S., Shimizu, K.-i \& Ueda, W. Selective synthesis of primary amines by reductive amination of ketones with ammonia over supported Pt catalysts. ChemCatChem 7, 921-924 (2015).

47. Liang, G. et al. Production of Primary Amines by Reductive Amination of Biomass-Derived Aldehydes/Ketones. Angew. Chem. Int. Ed. 56, 3050-3054 (2017).

48. Komanoya, T., Kinemura, T., Kita, Y., Kamata, Y. K. \& Hara, M. Electronic Effect of Ruthenium Nanoparticles on Efficient Reductive Amination of Carbonyl Compounds. J. Am. Chem. Soc. 139, 11493-11499 (2017).

49. Chatterjee, M., Ishizaka, T. \& Kawanami, H. Reductive amination of furfural to furfurylamine using aqueous ammonia solution and molecular hydrogen: an environmentally friendly approach. Green. Chem. 18, 487-496 (2016).

50. Reductive amination review. https://erowid.org/archive/rhodium/chemistry/ reductive.amination.html (2004)

51. Hintermann, L. Mignonac Reaction in Comprehensive Organic Name Reactions and Reagents (Wiley, 2010).

52. Jagadeesh, R. V. et al. MOF-derived cobalt nanoparticles catalyze a general synthesis of amines. Science 358, 326-332 (2017).

53. Hahn, G., Kunnas, P., de Jonge, N. \& Kempe, R. General synthesis of primary amines via reductive amination employing a reusable nickel catalyst. Nat. Catal. 2, 71-77 (2019).

54. Murugesan, K., Beller, M. \& Jagadeesh, R. V. Reusable nickel nanoparticlescatalyzed reductive amination for selective synthesis of primary amines. Angew. Chem. Int. Ed. 58, 5064-5068 (2019).

55. Lawrence, S. A. Amines: Synthesis, Properties and Applications (Cambridge University Press, 2004).

56. Ricci, A. Amino Group Chemistry: From Synthesis to the Life Sciences (Wiley$\mathrm{VCH}, 2008$ )

57. Smith, D. T., Delost, M. D., Qureshi, H. \& Njarðarson, J. T. Top 200 Pharmaceutical Products by Retail Sales in 2016. https://njardarson.lab.arizona.edu/sites/njardarson.lab.arizona.edu/files/ 2016Top200PharmaceuticalRetailSalesPosterLowResV3_0.pdf (2017).

58. Gunanathan, C. \& Milstein, D. Selective synthesis of primary amines directly from alcohols and ammonia. Angew. Chem. Int. Ed. 47, 8661-8664 (2008).

59. Imm, S., Bähn, S., Neubert, L., Neumann, H. \& Beller, M. An efficient and general synthesis of primary amines by ruthenium-catalyzed amination of secondary alcohols with ammonia. Angew. Chem., Int. Ed. 49, 8126-8129 (2010).

60. Pingen, D., Müller, C. \& Vogt, D. Direct amination of secondary alcohols using ammonia. Angew. Chem., Int. Ed. 49, 8130-8133 (2010).

61. Bähn, S. et al. The catalytic amination of alcohols. ChemCatChem 3, 1853-1864 (2011).

62. Müller, T. E. \& Beller, M. Metal-initiated amination of alkenes and alkynes. Chem. Rev. 98, 675-704 (1998)

63. Pohlki, F. \& Doye, S. The catalytic hydroamination of alkynes. Chem. Soc. Rev. 32, 104-114 (2003)

64. Müller, T. E., Hultzsch, K. C., Yus, M., Foubelo, F. \& Tada, M. Hydroamination: direct addition of amines to alkenes and alkynes. Chem. Rev. 108, 3795-3892 (2008).

65. Ma, X. \& Lei, M. Mechanistic insights into the directed hydrogenation of hydroxylated alkene catalyzed by bis(phosphine)cobalt dialkyl complexes. $J$. Org. Chem. 82, 2703-2712 (2017).

66. Yuwen, J., Chakraborty, S., Brennessel, W. W. \& Jones, W. D. Additive-free cobalt-catalyzed hydrogenation of esters to alcohols. ACS Catal. 7, 3735-3740 (2017).

67. Zhang, G., Scott, B. L. \& Hanson, S. K. Mild and homogeneous cobaltcatalyzed hydrogenation of C-C, C-O, and C-N bonds. Angew. Chem. Int. Ed. 51, 12102-12106 (2012)

68. Zhang, G., Vasudevan, K. V., Scott, B. L. \& Hanson, S. K. Understanding the mechanisms of cobalt-catalyzed hydrogenation and dehydrogenation reactions. J. Am. Chem. Soc. 135, 8668-8681 (2013).

69. Frisch, M. J. et al. Gaussian software, version 09 revision D01. (Gaussian Inc. Wallingford, CT, USA, 2009).

70. Becke, A. D. Density-functional thermochemistry. III. The role of exact exchange. J. Chem. Phys. 98, 5648-5652 (1993). 
71. Schäfer, A., Huber, C. \& Ahlrichs, R. Fully optimized contracted Gaussian basis sets of triple zeta valence quality for atoms Li to Kr. J. Chem. Phys. 100, 5829-5835 (1994).

72. Wohlfarth, C. Static Dielectric Constants of Pure Liquids and Binary Liquid Mixtures 17 (Springer, 2015).

73. Marenich, A. V., Cramer, C. J. \& Truhlar, D. G. Universal solvation model based on solute electron density and on a continuum model of the solvent defined by the bulk dielectric constant and atomic surface tensions. J. Phys. Chem. B 113, 6378-6396 (2009).

74. Grimme, S., Ehrlich, S. \& Goerigk, L. Effect of the damping function in dispersion corrected density functional theory. J. Comput. Chem. 32, 1456-1465 (2011).

\section{Acknowledgements}

We gratefully acknowledge the support of the European Research Council (ERC), the Federal Ministry of Education and Research (BMBF), the State of Mecklenburg-

Vorpommern and the Leibniz Association (Leibniz Competition, SAW-2016-LIKAT-1). We thank the analytical staff of the Leibniz-Institute for Catalysis, Rostock, for their excellent service. All data are available in the supplementary information.

\section{Author contributions}

K.M., R.V.J. and M.B. planned and developed the project. K.M., R.V.J., V.G.C., H.N. and M.B. designed the experiments. K.M. and V.G.C. performed catalytic experiments. Z.W. and H.J. carried out DFT calculations. A.S. performed X-ray crystallography analysis. K.M., R.V.J., M.B., H.N., Z.W. and H.J. wrote the manuscript. R.V.J. and M.B. supervised the project.

\section{Competing interests}

The authors declare no competing interests.

\section{Additional information}

Supplementary information is available for this paper at https://doi.org/10.1038/s41467 019-13351-7.

Correspondence and requests for materials should be addressed to M.B. or R.V.J.

Peer review information Nature Communications thanks Kuo-Wei Huang, Basker Sundararaju and the other, anonymous, reviewer(s) for their contribution to the peer review of this work. Peer reviewer reports are available.

Reprints and permission information is available at http://www.nature.com/reprints

Publisher's note Springer Nature remains neutral with regard to jurisdictional claims in published maps and institutional affiliations.

\begin{abstract}
(c) (1)
Open Access This article is licensed under a Creative Commons Attribution 4.0 International License, which permits use, sharing, adaptation, distribution and reproduction in any medium or format, as long as you give appropriate credit to the original author(s) and the source, provide a link to the Creative Commons license, and indicate if changes were made. The images or other third party material in this article are included in the article's Creative Commons license, unless indicated otherwise in a credit line to the material. If material is not included in the article's Creative Commons license and your intended use is not permitted by statutory regulation or exceeds the permitted use, you will need to obtain permission directly from the copyright holder. To view a copy of this license, visit http://creativecommons.org/ licenses/by/4.0/.
\end{abstract}

(C) The Author(s) 2019 